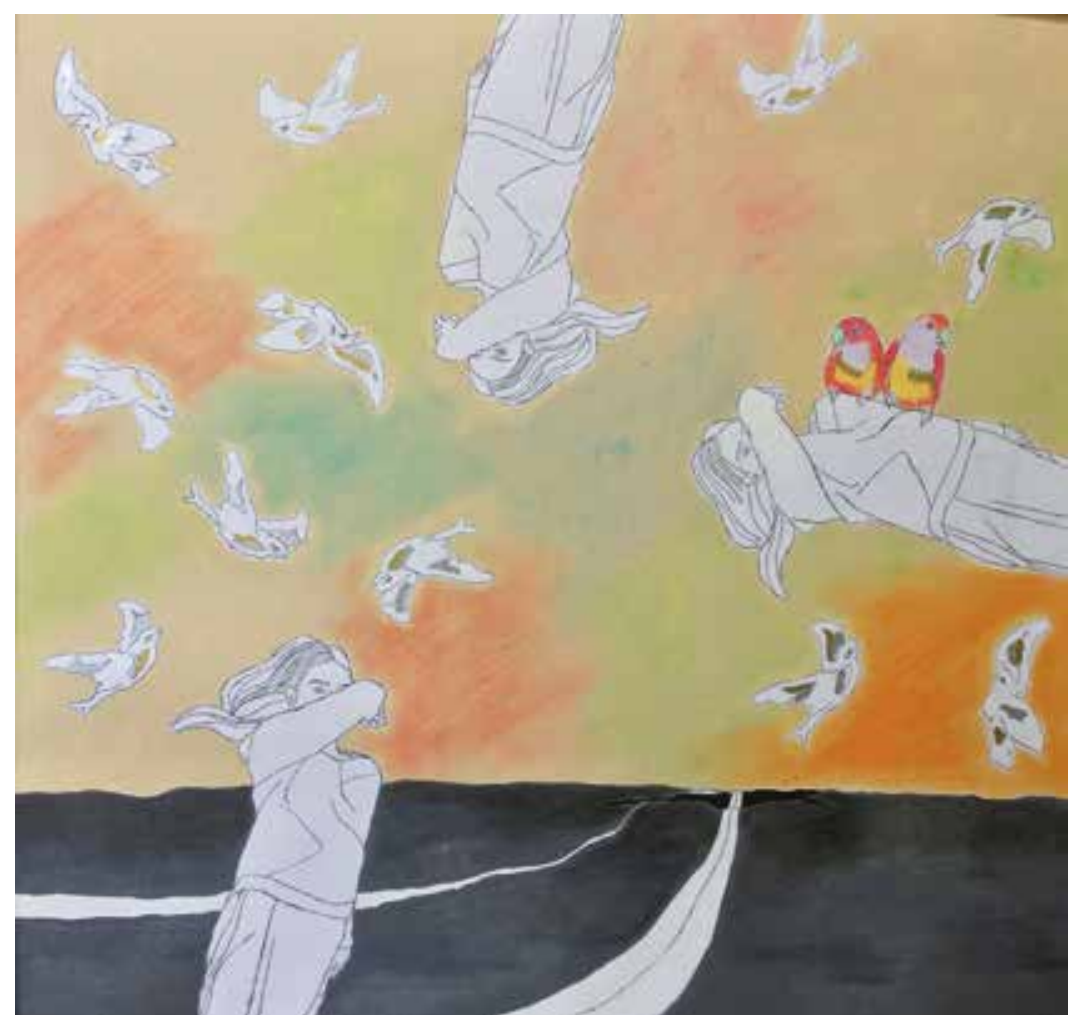

Pájaros en mi cabeza

polémico juego de pelota mesoamericano y las inmensas plazas que suelen acompañarlo?, ¿cuál es el motivo del colapso del periodo Clásico en las fértiles tierras bajas veracruzanas? Las soluciones se intuyen, mas nunca responden con alarmantes "últimas palabras" (tan características del rebasado positivismo).

Es loable el capítulo que discute el tabú por excelencia de nuestra área de estudio: los sistemas portuarios. Por décadas - por no decir desde siempre y con excepciones que se cuentan con una sola mano- el tema de la navegación prehispánica ha sido una premisa negada para los interesados en el ámbito. Lourdes Budar acepta el riesgo y ofrece algunos primeros resultados del tema.

El último apartado, "Modelos digitales y experimentales en la arqueología veracruzana”, examina en tres capítulos los vínculos que las nuevas tecnologías han com- partido con la arqueología, desde el análisis de artefactos metálicos precolombinos hasta la aplicación de modelos tridimensionales para apreciar mejor la resolución del estilo escultórico olmeca.

Cada una de las investigaciones de este libro aviva el fuego de un leño grandísimo llamado Costa del Golfo. El aporte de este -sin miedo a equivocarme- nuevo clásico de la arqueología mexicana es abrir puertas, resolver antes que estancar, plantear preguntas más que pretender dar respuestas $y$, lo más importante, alejar los revanchismos ideológicos de las diversas esferas intelectuales que versan sobre esta nuestra turbia Mesoamérica. Enhorabuena. LPyH

Maximiliano Sauza Durán es arqueólogo por la Uv. Premio Arte, Ciencia, Luz 2016 (Uv); Premio Teotihuacan 2017 (INAH). Actualmente estudia la maestría en Literatura Mexicana (Uv).

\section{Soledad, jel}

precio a pagiar?

\author{
Novela

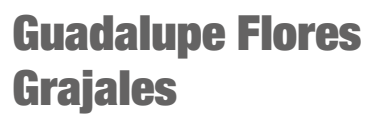

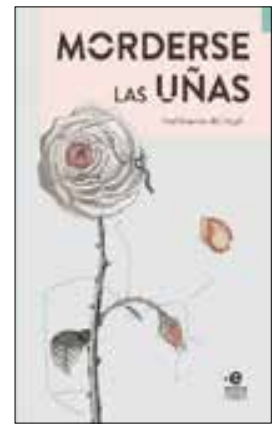

Itzel Guevara del Ángel,

Morderse las uñas, Bogotá, Pontificia Universidad Javeriana, 2017, 89 pp.

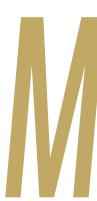

orderse las uñas es la primera novela escrita por Itzel Guevara del Ángel (Xalapa, 1976), autora del volumen de cuentos $S a n$ tas madrecitas (Conaculta, 2008, mención honorífica en los premios Nacional de Cuento Beatriz Espejo y Premio Dolores Castro) y quien ha sido incluida en varias antologías del cuento mexicano actual. Con su más reciente título obtuvo el segundo lugar del Premio Nacional de Novela Corta, organizado por la Universidad Javeriana de Bogotá, Colombia, en 2016. En su paso del cuento a la nouvelle, Itzel Guevara sigue priorizando la complejidad en el tratamiento y la construcción de su personaje principal, Leidy. La protagonista de Morderse las uñas nos narra uno de sus días, tan cotidiano como el de cualquier otra persona en la vida contemporánea. Un trabajo, un hogar, una mascota y una amiga, eso es lo 
que tiene o dice tener: lo único que posee.

A lo largo de los 15 apartados que integran el volumen nos introducimos poco a poco en el contexto de los padecimientos de la protagonista, desde los emocionales hasta los sociales. Ella posee toda la libertad para construir su identidad: elige su representación genérica, su nombre y, con base en las predicciones zodiacales, lleva a cabo la construcción cultural de su identidad sexual, producto del imaginario y la figuración mental propios (de lo individual a lo colectivo y no a la inversa). Esta metamorfosis implica para Leidy cierta libertad, aunque la condena a llevar una vida solitaria e introvertida, pues solo convive con su mascota y siente afecto o compasión por su amiga del trabajo.

A través de la vida de Leidy, la autora toca temas muy profundos, como la monotonía de la rutina o la complejidad de la identidad. Nos conduce a un tiempo y un lugar donde no hay nadie; nos hace sentir solos. Al acercarnos a la protagonista nos surge la siguiente pregunta: ¿Leidy busca la soledad o esta le es impuesta? ¿La elige voluntariamente como mecanismo de reflexión o la acepta al fin como un medio de liberación? La vida de Leidy nos hace comprender que somos víctimas de nuestros deseos y sueños, pero también de nuestros semejantes. Nos hace ver la lucha constante para sobrevivir. Morimos mil veces y mil veces renacemos.

Leidy busca ayuda en su compañera de trabajo y en su mascota, pero ninguna es capaz de llenar el vacío de su alma. Su vida es difícil, a veces triste y otras hostil. Por tanto, la soledad pareciera ser la línea temática en la novela; sin embargo, se ramifican otros temas como la discriminación, el acoso, la falta de empatía, las relaciones de poder ante la presencia de la muerte y las relaciones heteronormativas. Los funerales y la actividad como florista de Leidy nos la presentan totalmente humana, completa, rota, triste y en constante agonía.

La soledad y la incomunicación de la protagonista se configuran como puntos de partida insoslayables porque son la semilla de una misma cosmovisión, el centro que justifica y sostiene su narrativa: la nada de la civilización actual en los albores del siglo XXI. El mundo narrativo que se presenta es amenazante, agresivo, hostil; de esa imposibilidad de comunicación con él se deriva el aislamiento y, por tanto, la construcción de una identidad de mujer encerrada en un cuerpo y un espacio poco salvador.

Itzel Guevara propone un diálogo constante entre el transcurrir de la vida de la protagonista y la intención estética, y entre ambos discursos fluyen dolor, otredad, imagen, presencia o ausencia, entre otros, con el fin de revelar una visión realista de ser a través del otro y de lo otro.

En general, podemos identificar su poética en dos aspectos: una narrativa que plantea su compromiso estético y otra donde lo social se configura en relato que interfiere en lo artístico. En Morderse las uñas se expresa el mundo como un laberinto de posibilidades, de tiempos paralelos, de alternativas pasadas y futuras. Guevara del Ángel pasa al tono sombrío como símbolo de las ilusiones frustradas, destaca la ironía o lo grotesco -la "vida, no es ni buena ni mala"- pues, finalmente, "todo cabe en un jarrito, sabiéndolo acomodar", como reza el dicho; es decir, a pesar de las temáticas del dolor y de la soledad, también podemos descubrir el ingenio, la ironía fina y un pequeño toque de humor negro como características de su narrativa.

La protagonista se muestra tal cual: un ser humano con su miseria y su grandeza. Cada apartado permite descubrir que los momentos se multiplican y que, por lo regular, una cosa simboliza dos o más a la vez. Algo muy interesante, también, es que todos esos datos, listas $\mathrm{y}$ descripciones que aparecen al final de cada pequeño fragmento de la novela reflejan y complementan tanto los pensamientos como las emociones de Leidy durante el transcurso de la narración; la otra realidad: brutal y devastadora. El simple hecho de pensar que llegará otro día, seguido de otro y otro y otro más, sin la mínima posibilidad de descanso o cambio es lo que realmente causa el efecto de impacto. En ese sentido aplican las palabras de Juan Pablo Castel, protagonista de El túnel, de Ernesto Sábato, en boca de Leidy:

Los momentos de depresión en mí ocupan la mayor parte de mi existencia, momentos en que todo me parece horrible; la sociedad en que vivimos, espantosa, y en que se me ocurre que es casi imposible comunicarse con los otros, como si habláramos lenguas diferentes.

Lo anterior nos hace pensar en identidades atrapadas, en ausencias y presencias, en los seres que, al parecer, se sienten extranjeros en su propia tierra y en su cuerpo, en cuerpos y subjetividades femeninas o masculinas.

En suma, Morderse las uñas trata de la tarea tan sencillamente compleja de narrar la vida, un solo día en la vida de su protagonista que lucha por subsistir, por asegurar estar viva cada mañana. LPyH

Guadalupe Flores Grajales es profesora de tiempo completo de la $\mathrm{Fa}$ cultad de Letras Españolas de la Uv. Doctora en Humanidades (Teoría Literaria) por la UAM Iztapalapa. 